\title{
The Influence of External Stresses on the Transformation Behaviour in a Fe-Mn-Si Alloy
}

\author{
M. Andersson, R. Stalmans* and J. Ågren \\ Royal Institute of Technology, Department of Materials Science and Engineering, 10044 Stockholm, \\ Sweden \\ * Katholieke Universiteit Leuven, Department of MTM, de Croylaan 2, 3001 Heverlee, Belgium
}

\begin{abstract}
The influence of external stresses on the transformation behaviour has been studied for a polycrystalline Fe-3 IMn-5Si alloy exhibiting the $\gamma \rightarrow \varepsilon$ martensitic transformation. Samples have been loaded at temperatures above the $M_{s}$ temperature, cooled with a constant external load to a temperature below the $M_{s}$ temperature and subsequently heated without load to a temperature above the $A_{s}$ temperature of the alloy. Stress, strain and temperature have been continuously measured and transformation temperatures and strains have been determined from the change in strain during the transformation. It has been found that the $\mathrm{M}_{\mathrm{s}}$ temperature during cooling with load is not influenced by $0.3-2 \%$ plastic pre-deformation of the austenite whereas there is a substantial increase in the transformation strain, i.e. variants with a favourable orientation are enhanced by pre-strain of austenite.
\end{abstract}

\section{INTRODUCTION}

Fe-Mn-Si alloys in a certain composition range exhibit a shape memory effect due to the retransformation of stress induced $\varepsilon$ martensite to austenite during heating [1].

The purpose of the present study is to investigate the effect of pre-deformation and cycling on the transformation behaviour of $\mathrm{Fe}-\mathrm{Mn}$-Si alloys. Although this subject has been investigated by several researchers there are still some unresolved issues. For example, it seems rather well established that high plastic prestrains suppress the martensitic transformation, i.e. lower $M_{s}[2]$, but the effect of low prestrains is less clear. In most of the investigations $\varepsilon$ martensite is stress induced from a single phase $\gamma$ matrix during loading and subsequently retransformed during heating to a temperature above $A_{f}[3]$. In the present study $\varepsilon$ martensite has been induced by cooling a completely austenitic sample with a constant load applied. The sample has been unloaded at room temperature and subsequently heated without load to $190^{\circ} \mathrm{C}$, i.e. above $\mathrm{A}_{\mathrm{s}}$. The experiments have been repeated several times in order to study the effect of cycling on the transformation behaviour. The transformation temperatures and the transformation strains have been evaluated from the change in strain during cooling and heating. Both the stress dependence of $M_{s}$ when the amount of plastic pre-deformation of the austenite is very low and the influence of low prestrains of the austenite, up to $2 \%$, on the transformation behaviour are investigated.

\section{EXPERIMENTAL PROCEDURE}

The alloy was prepared by induction melting under argon atmosphere and cast in a copper mould. The alloy has a nominal composition of 64.38 mass $\% \mathrm{Fe}, 30.67$ mass\% $\mathrm{Mn}$ and 4.95 mass\% $\mathrm{Si}$. The alloy was annealed $0.5 \mathrm{~h}$ at $1050{ }^{\circ} \mathrm{C}$, in argon gas atmosphere, before it was reduced $70 \%$ by hot rolling. Thereafter it was homogenised at $1000^{\circ} \mathrm{C}$ for $24 \mathrm{~h}$ in evacuated quartz tubes.

Tensile test specimens with dimensions $2 * 4 * 85 \mathrm{~mm}^{3}$ were machined from the homogenised material. During machining the specimens became slightly bent. In order to straighten the specimens they were 
fixed in a straight position at room temperature, heat treated in air for $10 \mathrm{~min}$ at $800^{\circ} \mathrm{C}$ and air cooled to room temperature in the constrained condition.

After this procedure the specimens were heat treated $30 \mathrm{~min}$ at $900^{\circ} \mathrm{C}$, in an evaquated quartz tube, followed by water quenching.

A computer controlled testing apparatus, developed for the purpose of the thermomechanical testing of shape memory samples (details in [4]), was used. This testing apparatus allows a combined programming of the sample temperature and the force on the sample as a function of time. The deformation mode is uniaxial tension and the sample is immersed in a silicon oil bath, allowing an accurate temperature control between $25^{\circ} \mathrm{C}$ and $200^{\circ} \mathrm{C}$. A thermocouple is connected to the sample with a heat conductive tape. The gage length of the specimens was close to $50 \mathrm{~mm}$. Gage length, force on the sample and sample temperature are sampled twice a second and processed by a computer.

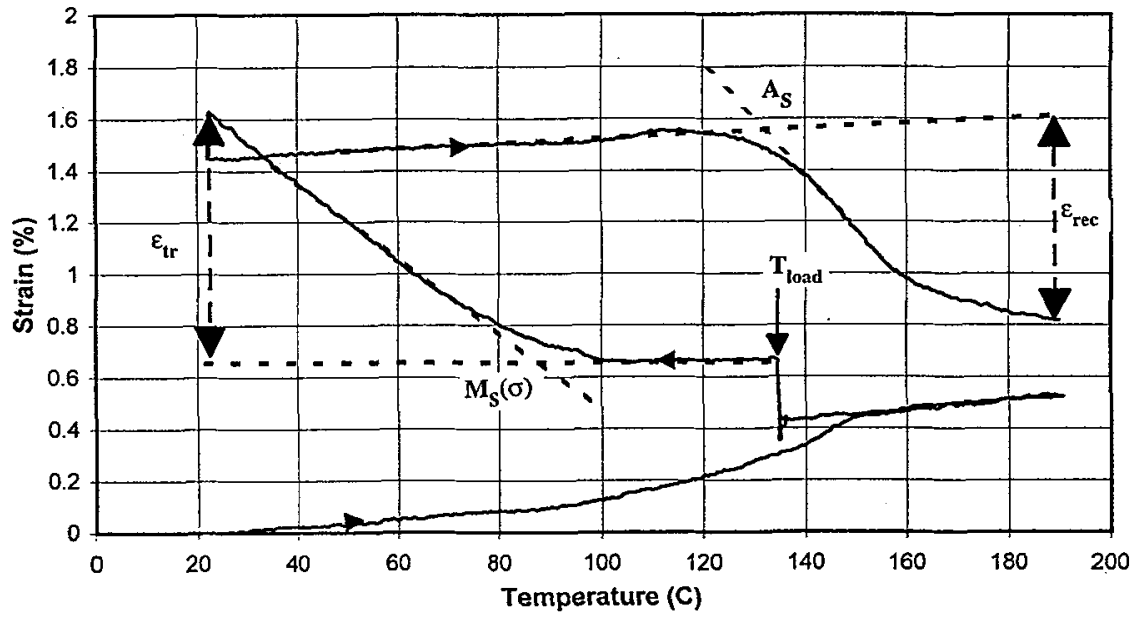

Figure 1 The strain-temperature relation during a "cooling with constant load experiment".

Figure 1 illustrates the general procedure of the thermomechanical experiments. First the sample is heated with a low load, $1 \mathrm{MPa}$, to $190^{\circ} \mathrm{C}$. Then the sample is cooled to the temperature, $\mathrm{T}_{\text {load }}$, where the stress is increased at a constant rate of $0.5 \mathrm{MPa} / \mathrm{s}$ to $\sigma_{\text {app. }}$. Thereafter the sample is cooled with constant load to room temperature where the sample is unloaded to $1 \mathrm{MPa}$. Experiments have been performed for different values of the temperature $T_{\text {load }}$ and for different values of the applied stress $\sigma_{\text {app}}$, see Table 1 . In some of the experiments the samples were reheated to $190^{\circ} \mathrm{C}$ and the treatment was repeated 5 times in order to study the effect of cycling on the transformation behaviour.

Table $1 \quad$ Cyclic cooling with constant load experiments.

\begin{tabular}{cccc}
\hline Specimen name: & $\mathrm{T}_{\text {load }}\left({ }^{\circ} \mathrm{C}\right)$ & $\sigma_{\text {app }}(\mathrm{MPa})$ & Cycles \\
\hline $190-184$ & 190 & 184 & 6 \\
$160-184$ & 160 & 184 & 6 \\
$135-184$ & 135 & 184 & 6 \\
$120-169$ & 120 & 169 & 6 \\
$130-123$ & 130 & 123 & 6 \\
\hline
\end{tabular}

$M_{s}(\sigma), A_{s}, A_{f}$, the transformation strain $\varepsilon_{t r}$, during cooling with load and the recovery strain $\varepsilon_{\text {rec }}$, during heating without load are determined by an interception line method as indicated in Fig. 1. 
The transformation temperatures, $M_{s}$ and $A_{s}$, before thermomechanical cycling, were determined to be 34 ${ }^{\circ} \mathrm{C}$ and $137^{\circ} \mathrm{C}$ respectively by dilatometer measurements. Some of the cycled samples were heated in the dilatometer in order to study the transformation behaviour above $190^{\circ} \mathrm{C}$, i.e. the maximum heating temperature in the cycling experiments.

\section{RESULTS}

\subsection{The stress-temperature diagram}

Figure 2 shows (i) the temperature dependence of the $\sigma_{0.2}$ yield stresses for the experiments where the loading at $\mathrm{T}_{\text {load }}$ resulted in plastic yielding, represented by filled squares, and (ii) the stress dependence of $M_{s}, M_{s}(\sigma)$, for the experiments where the loading resulted in elastic deformation only, represented by filled circles. The thermal martensitic transformation temperature measured by dilatometer measurements is plotted with a filled triangle in Fig. 2. The open circle in Fig. 2 indicates a sample in which the austenite has been deformed $0.3 \%$ before cooling with load. The highest temperature, $\mathrm{M}_{\mathrm{s}}^{\sigma}$, where a stressassisted transformation without prior plastic yielding can occur, i.e. the intersection between the lines representing the elastic stress dependence of $\mathrm{M}_{s}$ and the temperature dependence of the $\sigma_{0.2}$ yield stress of the austenite, is $89^{\circ} \mathrm{C}$ in the present alloy, see Fig. 2. The elastic stress dependence of $\mathrm{Ms}, \mathrm{d} \sigma / \mathrm{dM}$, and the temperature dependence of the $\sigma_{0.2}$ yield stress of the austenite, $\mathrm{d} \sigma^{\gamma} / \mathrm{dT}$, are $3.95 \mathrm{MPa} /{ }^{\circ} \mathrm{C}$ and -0.60 $\mathrm{MPa} /{ }^{\circ} \mathrm{C}$ respectively.

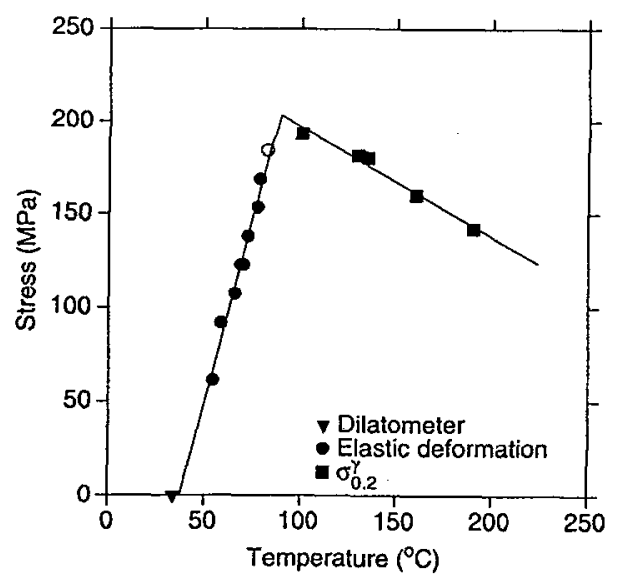

Figure 2 The stress-temperature relation for the Fe-31Mn-5Si alloy.

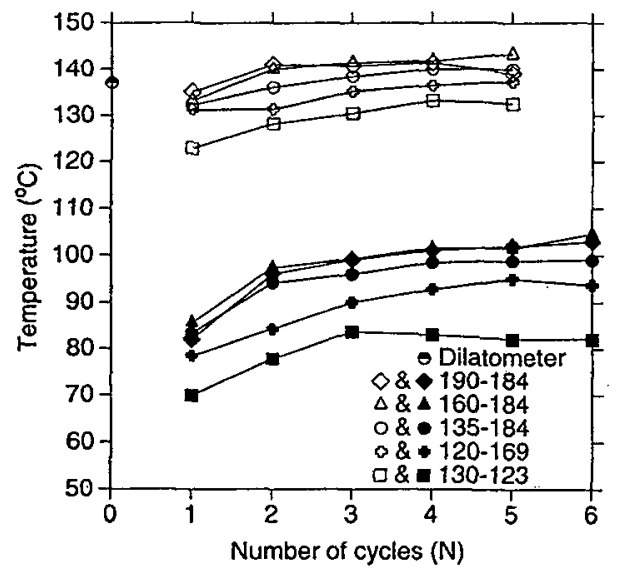

Figure $3 M_{s}$ and $A_{s}$ as a function of number of cycles.

\subsection{The influence of thermomechanical cycling on the transformation behaviour}

In order to study the effect of cycling on the transformation behaviour five specimens with different loading temperatures, $T_{\text {load, }}$, and applied stresses, see Table 1 , were cycled 6 times. The five samples give different amounts of plastic yielding during the first loading at $T_{\text {load }}$, see table 2 . Three of the samples received different amounts of plastic deformation and were cooled with the same stress, $\sigma_{\text {app }}$, and thus the effect of plastic yielding of the austenite on the transformation behaviour can be studied. The plastic deformations at $T_{\text {load }}$ after the first loading in specimens 120-169 and 130-123 are small, below the experimental limit, and thus the values are not given in table 2. Equally low values of plastic deformation are found in all of the specimens after the second to sixth cycle. 
Table 2 Plastic strain after the first deformation at $\mathrm{T}_{\text {load }}$ for the cycled specimens.

\begin{tabular}{lccccc}
\hline Sample & $190-184$ & $160-184$ & $135-184$ & $120-169$ & $130-123$ \\
\hline Plastic strain(\%) & 2.0 & 0.6 & 0.3 & - & - \\
\hline \hline
\end{tabular}

Specimens $190-184,160-184,135-184,120-169$ and 130-123 will be represented by a diamond, a triangle, a circle, a cross and a square respectively in the following figures. The transformation temperatures $M_{s}$ and $A_{s}$, indicated by a filled respectively an open symbol, are shown as a function of number of cycles in Fig. 3.

A comparison between the specimens that are cooled with the same $\sigma_{\text {app }}$ shows that the $M_{s}$ temperature, during the first cooling with load, is not influenced by small, $0.3-2 \%$, plastic pre-deformations of the austenite. In all the specimens $\mathrm{M}_{\mathrm{s}}$ increases slightly, about $15^{\circ} \mathrm{C}$, with increasing number of cycles.

The $A_{s}$ temperature during the first heating to $190^{\circ} \mathrm{C}$ before loading is evaluated as $137^{\circ} \mathrm{C}$, see the half filled circle in Fig. 3, from dilatometer measurements, since the expansion during the $\varepsilon \rightarrow \gamma$ transformation was too small to be accurately evaluated by the present experimental set up. Fig. 3 shows that $A_{s}$ during the first heating after cooling with load is approximately $132^{\circ} \mathrm{C}$ for all of the specimens except for the specimen $130-123$ in which it is $10^{\circ} \mathrm{C}$ lower. $A_{s}$ is only slightly increased, $10^{\circ} \mathrm{C}$, with increased amount of cycles in all the specimens.

The $A_{f}$ temperature, the temperature where all the martensite formed during cooling with load has transformed completely to austenite, for specimens $130-123$ and $120-169$ is evaluated as $145^{\circ} \mathrm{C}$ and $155^{\circ} \mathrm{C}$ respectively. $A_{f}$ is raised above $190^{\circ} \mathrm{C}$ for the specimens $190-184,160-184$ and 135-184 and this behaviour is confirmed by heating the cycled specimens in a dilatometer to $300^{\circ} \mathrm{C}$.

The transformation strain induced during cooling with load, $\varepsilon_{\mathrm{tr}}$, and the strain recovered during subsequent heating, $\varepsilon_{\text {rec }}$, as functions of number of cycles are shown in Figs. 4 and 5. Specimen 130-123 shows a constant $\varepsilon_{\mathrm{tr}}$ during cycling. The four other samples show a decrease in $\varepsilon_{\mathrm{tr}}$ with increasing number of cycles. A comparison between the three samples that have been cooled with the same $\sigma_{\text {app }}$ clearly shows that the sample with the largest plastic predeformation of the austenite gives the largest transformation strain in the following cycles.

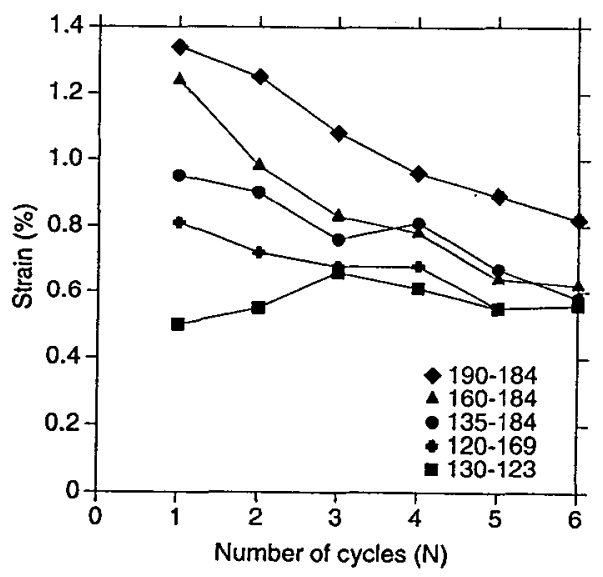

Figure $4 \varepsilon_{t r}$ as a function of number of cycles.

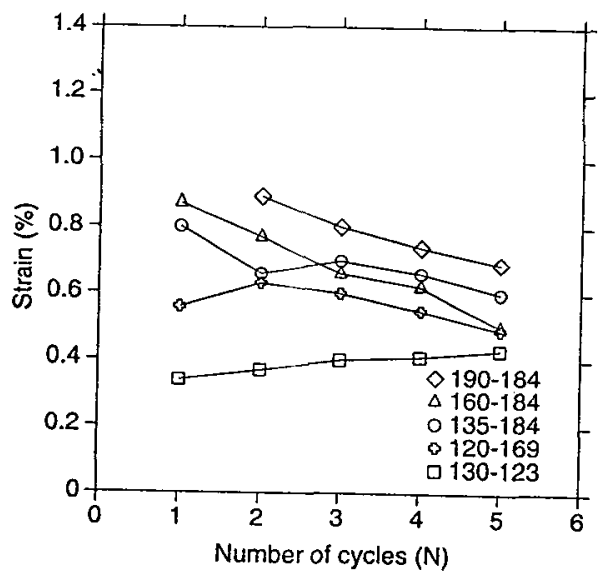

Figure $5 \varepsilon_{\text {rec }}$ as a function of number of cycles. 
In all the specimens the recovery strain in Fig. 5 shows a similar behaviour during cycling as the transformation strain in Fig. 4.

\section{DISCUSSION}

\subsection{The stress-temperature diagram}

The positive slope in fig. 2 of the stress-temperature diagram below $M_{s}^{\sigma}$ is due to a stress assisted growth of martensite [5], i.e. growth occurs with the aid of the applied stress and $M_{s}$ increases with the applied stress. The relation between $M_{s}$ and applied elastic stresses will be analysed in detail in a coming paper and will thus not be discussed further in the present paper. In the present paper fig. 2 is mainly presented in order to illustrate the discussion regarding the effect of prior plastic strain on the transformation behaviour.

In the temperature region above $\mathrm{M}_{\mathrm{s}}^{\sigma}$ the $\sigma_{0.2}$ yield stress shows a negative temperature dependence. The temperature dependence of the yield strength of austenite, $\mathrm{d} \sigma^{\gamma} / \mathrm{dT}$, is $-0.60 \mathrm{MPa} /{ }^{\circ} \mathrm{C}$ in the present investigation. This value is in reasonable agreement with the previously reported results in Fe-Mn-Si alloys by Tomota et al. [6], $-0.75 \mathrm{MPa} /{ }^{\circ} \mathrm{C}$, and Otsuka et al. [7], $-0.98 \mathrm{MPa} /{ }^{\circ} \mathrm{C}$.

\subsection{The influence of thermomechanical cycling on the transformation behaviour}

Tsuzaki et al. [8] have reported that the $\sigma_{0.2}$ proof stress at $17^{\circ} \mathrm{C}$ is decreased by pre-straining the austenite $0.7-4 \%$ at $300^{\circ} \mathrm{C}$. Their conclusion is that the critical stress for the martensitic transformation is decreased by applying a small amount of pre-strain on the austenite, i.e. the martensitic transformation is enhanced and one might expect an increase in $M_{s}$. However, the present investigation shows that $M_{s}$ during cooling with load is not influenced by $0.3-2 \%$ plastic pre-deformation of the austenite and it may thus seem as the present investigation is in disagreement with the results of Tsuzaki et al. As indicated by the transformation strain $\varepsilon_{t \mathrm{t}}$ plotted in Fig. 4 this is not necessarily the case because a pre-deformation of only $2 \%$ increases $\varepsilon_{\text {tr }}$ markedly, i.e. the martensite variants with a favourable orientation are substantially enhanced by predeformation of austenite. Moreover, a closer examination of the strain-temperature curves reveals that whereas predeformation of austenite increases $\varepsilon_{\mathrm{tr}}$, it has a very small effect on the onset of the transformation. It may also be noted that the $0.2 \%$ deformation at the $\sigma_{0.2}$ proof stress corresponds to a considerable amount of martensite, see fig. 1, and if the definition of $\mathrm{M}_{s}$ had been based on $0.2 \%$ strain $\mathrm{M}_{s}$ had fallen to much lower temperatures and had reflected not only the onset of the transformation but also the magnitude of the transformation strain $\varepsilon_{\mathrm{tr}}$. We may thus conclude that the present results are not in disagreement with the results of Tsuzaki et al. but add further insights.

$A_{s}$ is not markedly influenced by small pre-deformation of the austenite before inducing martensite by cooling with load. Specimen 130-123, which gives the smallest transformation strain during cooling with load, also has the lowest $A_{s}$ temperature. The small transformation strain will not give rise to any plastic deformation of the austenite surrounding the $\varepsilon$ martensite and this might be the reason for the lower $A_{s}$ temperature in this alloy.

From their cooling with constant load experiments Tomota et al.[9] showed that a small plastic predeformation of the austenite is effective in obtaining a large transformation elongation. The present results show that if three samples are cooled with equally applied load the transformation strain is largest in the sample with the largest pre-deformation of the austenite. This result is in good agreement with the previous observations.

In specimens 190-184, 160-184 and 135-184 the $A_{f}$ temperature after cooling with load is higher than 190 ${ }^{\circ} \mathrm{C}$, the highest temperature during the present thermo-mechanical treatment. After each cycle martensite 
is left in the structure and the stress induced martensite in the next cycle is formed from a two phase structure of $\gamma$ and $\varepsilon$. The formation of stress induced martensite from the two phase structure does result in a $\varepsilon_{\mathrm{tr}}$ smaller than the maximum attainable. A higher maximum heating temperature during the thermomechanical cycling would thus diminish the marked decrease in $\varepsilon_{\mathrm{tr}}$ with cycling for these specimens. But, although specimens 130-123 and 120-169 are fully austenitized in every heating cycle, the former shows an almost constant $\varepsilon_{\mathrm{tr}}$ whereas the latter shows a small decrease in $\varepsilon_{\mathrm{tr}}$ with cycling. Thus, a higher maximum heating temperature will probably not be sufficient in order to obtain a constant $\varepsilon_{\mathrm{tr}}$ with cycling in specimens $190-184,160-184$ and 135-184.

The slightly higher $A_{f}$ temperature of specimen 120-169 as compared to 130-123 is probably due to the increased $\varepsilon_{\mathrm{tr}}$, i.e. increased amount of stress induced martensite, with increased applied stress. A specimen with a larger amount of martensite needs to be heated to a higher temperature in order to completely transform back to austenite.

The fact that both $M_{s}$ and $A_{s}$ show a small increase with number of cycles indicates that the $\varepsilon$ phase is slightly stabilised by the thermomechanical treatment.

\section{CONCLUSIONS}

Martensite variants with favourable orientation are enhanced by $0.3-2 \%$ plastic pre-strain of austenite whereas the onset of the martensitic transformation is hardly affected at all. Cycling has not a large effect on the transformation temperatures but for samples which have been plastically pre-strained there is a strong decrease both in transformation strain and in recoverable strain.

\section{Acknowledgements}

The thermomechanical experiments were performed at department MTM, KU.-Leuven, Belgium. The travel to Leuven was financed by a Scholarship from Jernkontoret in Sweden. This project is financed by the Swedish National Board for Industrial and Technical Development. Rudy Stalmans acknowledges the Fund for Scientific Research-Flanders for a grant as Postdoctoral Fellow.

\section{References}

[1] Sato A., Chisima E.,Soma K. and Mori T., Acta Met. 30 (1982) 1177-1183.

[2] Tsuzaki K., Fukasaku S., Tomota Y. and Maki T., Mater. Trans. JIM 32 no. 3 (1991) 222-228.

[3] Maki T., Tsuzaki K., "Transformation behaviour of $\varepsilon$ martensite in Fe-Mn-Si shape memory alloys", ICOMAT, Monterey 1992,C. M. Wayman and J. Perkins Eds., (Monterey Inst. of Adv. Studies, Monterey, 1993) pp. 1151-1162.

[4] Stalmans R., Van Humbeeck J. and Delaey L., Acta metall. mater. 40 (1992) 501-511.

[5] Olson G. B., Cohen M., J Less-Common Metals 28 (1972) 107-118.

[6] Tomota Y., Ryufuku S., Riao M., J. Soc. Mater. Jpn. 40 (1991) 27-33.

[7] Otsuka H., Murakami M., Matsuda M.,'Improvement in the shape memory effect of Fe-Mn-Si alloys by the thermomechanical treatment", MRS Int. Mtg. Adv. Mat., Tokyo 1988, M. Doyama, S. Somiya. and R. Chang Eds.,(MRS, Pittsburgh, 1989) 9 pp. 451-456.

[8] Tsuzaki K., Murakami Y., Natsume Y. and Maki T., "Role of pre-straining of austenite in the im provement of shape memory effect in an Fe-33Mn-6Si alloy", Adv. Mat. '93 V/B Shape memory mater., Tokyo 1993, K. Otsuka and Y. Fukai Eds.,(Trans. Mat. Res. Soc. Jpn., Elsevier Science B.V, The Netherlands, 1994) 18B pp. 961-964.

[9] Tomota Y., Nakagawara W., Tzusaki K. and Maki T., Scripta. Met. 26 (1992) 1571-1574. 